\title{
PURITY OF EBR-II PRIMARY COVER GAS
}

\author{
by
}

D. C. Cutforth and W. H. Perry

\author{
EBR-II Project \\ Argonne National Laboratory \\ Argonne, İilinols - Idaho Fails, Idaho
}

November 1971

Thts roport was prepared as an acecunt of work sponsored by the United. States Government. Neithes the United Statea nos the United States Atomic Energy Commsaston, nor any of their employees, nor any of thef contractors, subcontractors, or their employees, makes any warranty, express or inplied, or assumes any leqd liability os resporsibiliey. for the accuracy, completenose or usefulness of any information, apparatus, product or process disclosed, or represents that its use would not infringe privately owned rights.

Work performed under the ausplces of the U. S. Atomic Energy Commission 
TABLE OF CONTENTS

Page

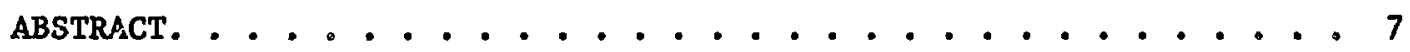

I. INTRODUCTION. ................. 7

II. NITRUgen CONTAMTNATION. .............. 8

A. Behavior of Nitrogen Concentration under Various Plant

Conditions. . . . . . . . . . . . . . 8

1. Purge of Primary Cover Gas. . . . . . . . . . 8

2. Restricted Fuel Handling. . . . . . . . . 11

3. Unrestricted Fuel Handling. . . . . . . . . 14

4. Reactor Operation . . . . . . . . . . 17

5. Leakage through the FUM-ACS and FGM Systems . . . . . 19

6. Miscellaneous ............... 19

B. Summary of Data from the Gas Chromatograph. . . . . . . 20

C. Studies on Nitridation. . . . . . . . . . . 20

III. HYDROGEN AND OXYGEN CONTAMINATION . . . . . . . . . 27

IV. CONCLUSIONS AND RECOMMENDATIONS ............ 2 ?

ACKNOWLEDGEMENTS. . . . . . . . . . . . . . . 29

REFERENCES. ...................... 31 


\section{LIST OF FIGURES}

No.

Title

Page

1. EBR-II Argon Distribution System. . . . . . . . . . . . . 9

2. EBR-IJ Fission-gas Monitor (FGM) System . . . . . . . . . . , 10

3. Nitrogen Concentration in EBR-II Primary Covet Gas during a Purge of Approximately $10 \mathrm{cfh}$. . . . . . . . . . . . . 12

4. Flow Diagram of Argon Cooling System for Fuel-unloading Machine . . . . . . . . . . . . . . . 13

5. Nitrogen Concentration in EBR-II Primary Cover Gas during Restricted Fuel Handling. . . . . . . . . . . . . . 15

6. Typical Behavior of Nitrogen Concentration in EBR-II Primary Cover Gas during Unrestricted Fuel Handling . . . . . . . . . 16

7. Typical Nitrogen Concentration In EBR-II Primary Cover Gas during Reactor Operation. . . . . . . . . . . . . . . 18

8. Nitrogen Concentration in EBR-II PrImary Cover Gas: March 1968-September 1968 . . . . . . . . . . . . . 21

9. Nitrogen Concentration in EBR-II Primary Cover Gas: October 1968-March 1969 . . . . . . . . . . . . . . . 22

10. Nitrogen Concentration in EBR-II Primary Cover Gas: Apri1 1969-September 1969 . . . . . . . . . . . . . 23

11. Nitrogen Concentration in EBR-II Primary Cover Gas: October 1969-March 1970 . . . . . . . . . . . . . 24

12. Nitrogen Concentration in EBR-II Prima:y Cover Gas: April 1970-September 1970 . . . . . . . . . . . . 25

13. Nitrogen Concentration in EBR-II Primary Cover Gas: October 1970-March 1971 . . . . . . . . . . . . . 26

14. Typical Increases in Hydrogen and Oxygen Concentration in EBR-II Primary Cover Gas When Fuel Transfer Port Is Opened. . . 28 
PURITY OF EBR-II PRIMARY COVER GAS

by

D. C. Cutforth and W. H. Perry

\section{ABSTRACT}

The primary cover gas of Experimental Breeder Reactor II (EBR-II) is continuously monitored for oxygen, nitrogen, and hydrogen content. A program was started in March 1968 to identify the sources of these impurities and to reduce their level in the cover gas. At that time, the nitrogen coincentration averaged about $6000 \mathrm{ppm}$ with short-term levels as high as $20,000 \mathrm{ppm}$; the hydrogen concentration was occasionally as high as $400 \mathrm{ppm}$. Nitrogen (from air) was found to be introduced primarily through the argon cooling system of the fuel-unloading machine and through the fuel-holddown packing gland during fuel-transfer operations in the primary tank. The principal source of hydrogen (moisture) was traced to inadequate drying of the interbullding fuel-transfer cask (or coffin). Modifications of equipment have significantly reduced the frequency and magnitude of inleakages of impurities.

\section{INTRODUCTION}

The investigation discussed in this report was started in March 1968 as part of an effort to formulate specifications for the primary cover gas in 1iquid-metal-cooled fast breeder reactors. Nitrogen buildup was of part1cular interest because nitridation of stalnless steel is known to occur at high temperatures and high nitrogen concentrations, and, unlike hydrogen and oxygen, nitrogen is removed from the primary system only by dilution by an argon purge into the primary tank.

The first phase of the Investigation was to identify the major sources of impurities in the EBR-II cover gas. Comparisons of variations in impurity levels with plant logs indicated that significant inleakage of Impurities occurred during fuel-handling operations. The various sources are discussed in Sec. II. 
As the investigation progressed, results indicated that the nitrogen in the cover gas was not a serious problem insofar as nitridation of reactor materials is concerned. However, the introduction of oxygen and hydrogen Into the cover gas was obviously detrimental to coolant purity, so plant improvements were made to reduce the volume of air inleakage to the primary cover gas. Nitrogen was used as a "tag" to evaluate the improvements, because it is the only impurity not removed from the cover gas by reaction with the liquid sodium coolant.

Plant improvements were made over a relatively long period of time and only when compatible with the schedule for reactor operation. The importance of reactor operation, the complexity of the EBR-II facility, and the lack of accurate measuring devices in some components of the system have made some interesting tests impractical to complete. However, air inleakage to the primary tank has been reduced considerably.

The primary cover gas is argon. Makeup gas does not exceed the following maximum allowable impurity levels (in ppm by volume): $\mathrm{H}_{2} \mathrm{O}, 13$; nitrogen, 20; carbon-bearing gases, 5; hydrogen, 1 . The primary covergas system has a total geometrical volume of about $1.8 \times 10^{7} \mathrm{~cm}^{3}$. Figure 1 shows the flow diagram for the argon distribution system; the system is completely described in Refs. 1-5.

Cover-gas purity is monitorea by a Beckman Model 320-D gas chronatograph attached to the supply of the fission-gas monitor (FGM) as shown in Fig. 2. A gas sample is analyzed once every $4 \mathrm{~min}$, and the results are recorded on a strip-chart recorder.

\section{NITROGEN CONTAMINATION}

\section{A. Behavior of Nitrogen Concentration under Various Plant Conditions}

\section{Purge of Primary Cover Gas}

The primary cover gas is purged with fresh argon occasionally to reduce: excessively high nitrogen concentrations; radioactivity levels; or the nitrogen level to a very low value for system studies on air inleakage. 


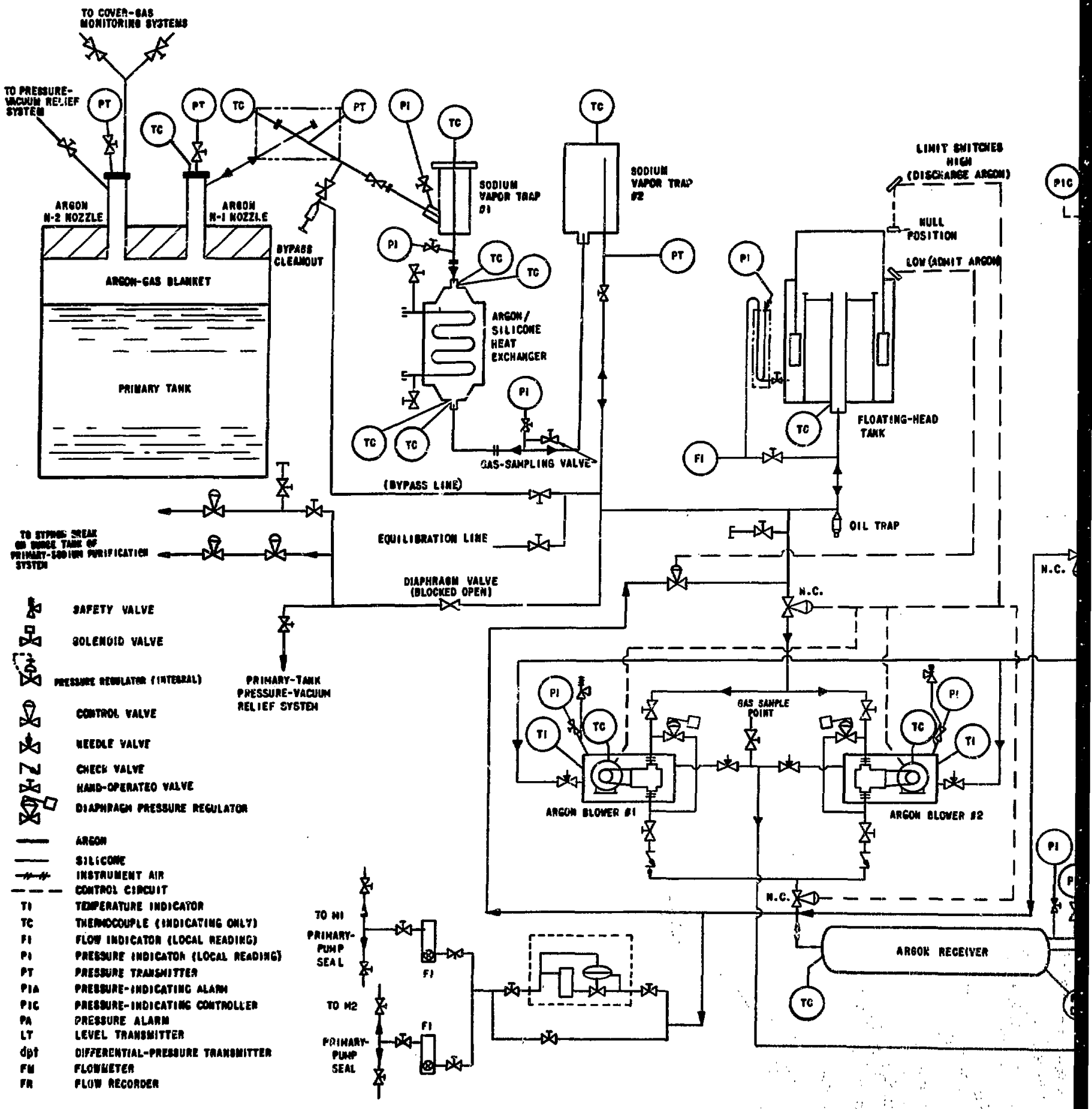

Fig. I. EBR-II Argon Distribution 


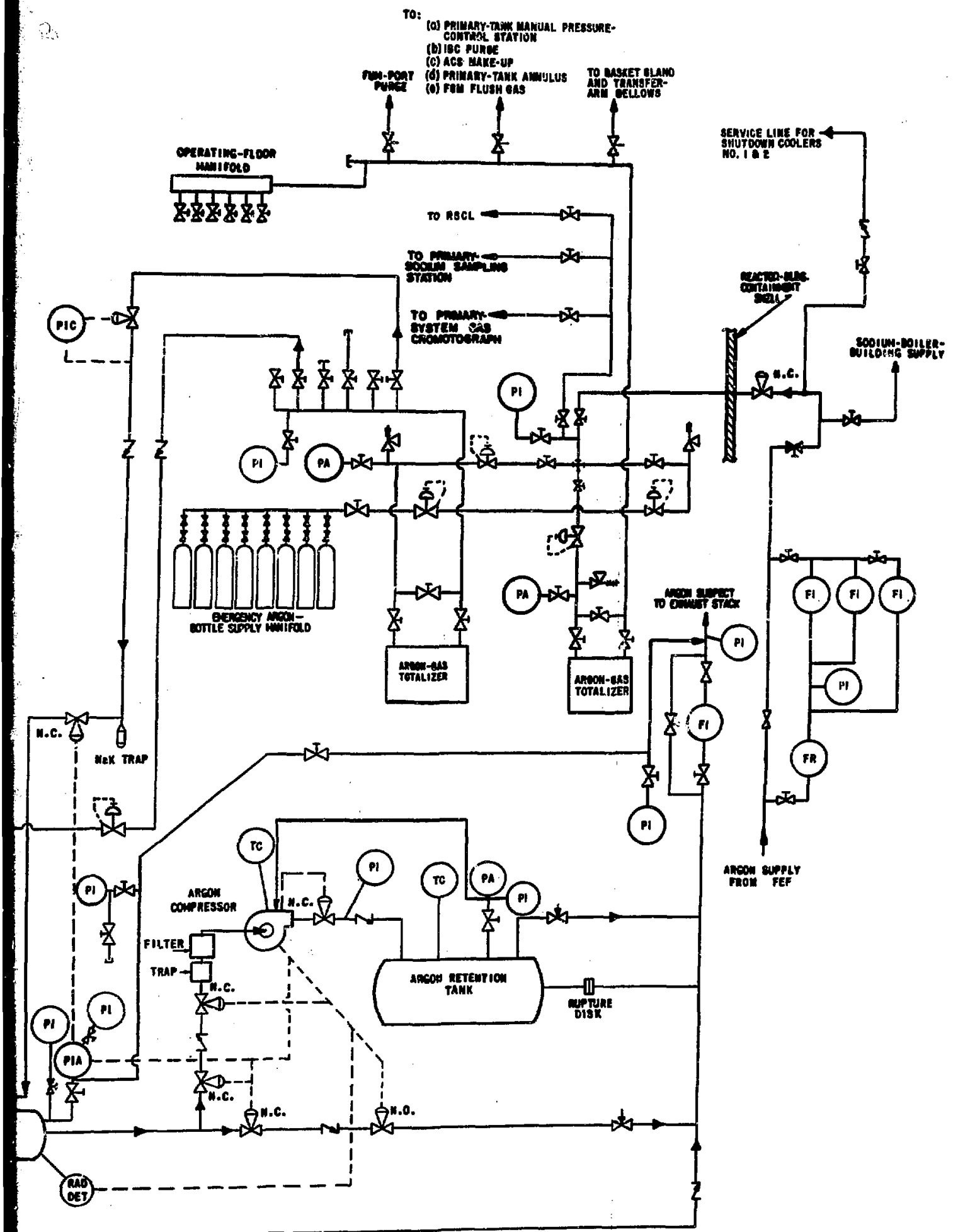




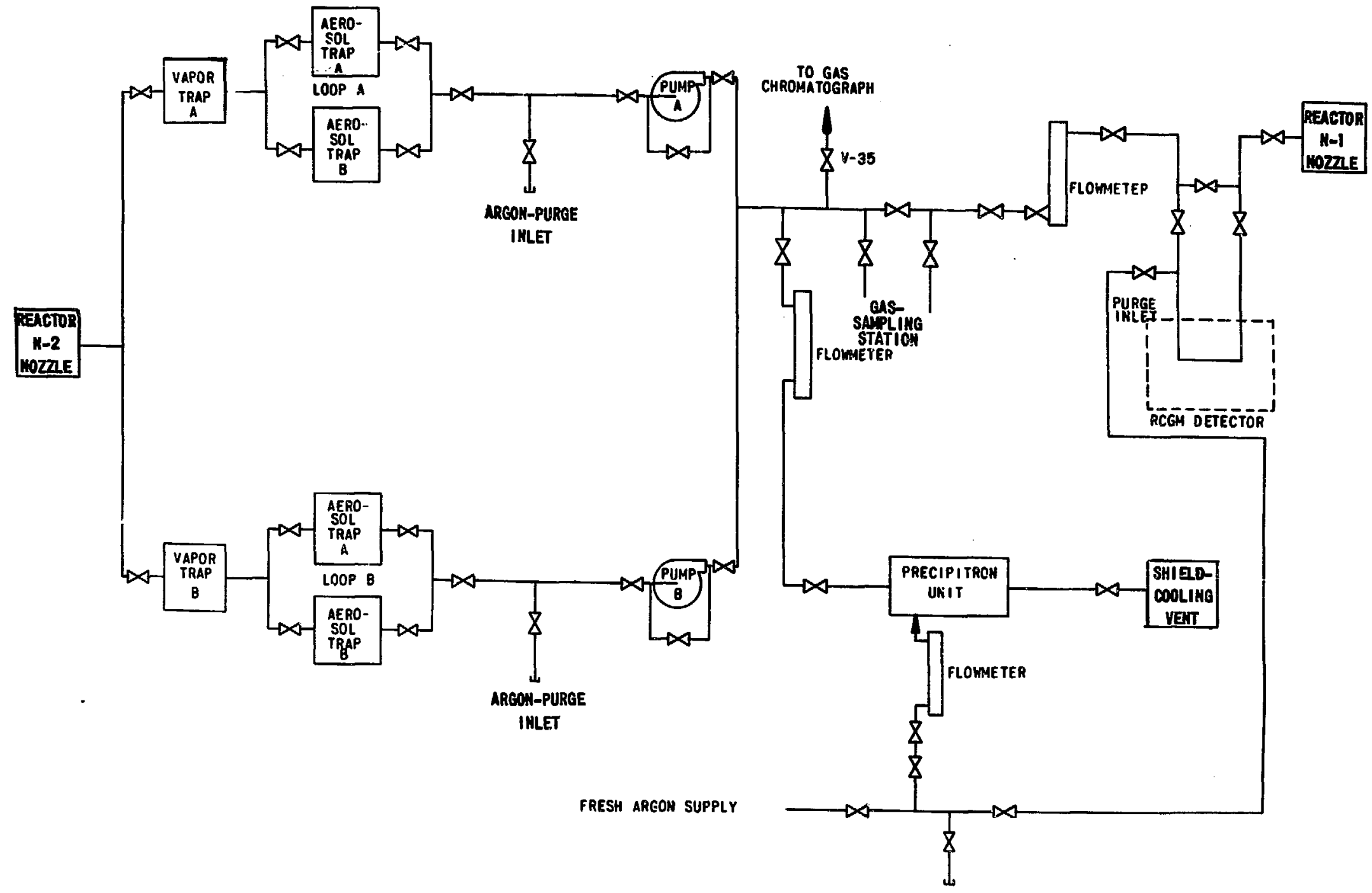

Fig. 2. EBR-II Fission-gas Monitor (FGM) System 
Two methods are used to purge the primary cover gas. In the first method, the cover gas is exhausted to the stack at a rate of about $6 \mathrm{cfh}\left(47 \mathrm{~cm}^{3} / \mathrm{sec}\right)$. Makeup comes from a combination of the purge to the primary-pump seals and the flow to the primary tank from the floatinghead tank through the N-1 nozzle (see Fig. 1). Figure 3 shows the nitrogen concentration as a function of time for a typical purge. This purge, as with all other purges of the primary cover gas, was terminated before the nitrogen concentration reached a definite equilibrium value.

The second method of purging the primary cover gas is to first establish that the argon in the argon cooling system of the fuel-unloading machine (FUM-ACS) is of high purity and then $\mathrm{mix}$ the gas in the FUM-ACS with the primary cover gas. (Figure 4 shows the argon-system piping for the FUM-ACS.) This purging method reduces inpurity levels very quickly by dilution, but the limited volume in the FUM-ACS places a limit on the amount of impurity reduction that can be achieved in one mixing operation. The gas in the FUM-ACS can be cleaned up and again mixed with the primary corer gas, but this procedure is seldom used.

\section{Restricted Fuel Handling}

Restricted fuel handling, the mode of operation in which subassemblies are exchanged between the reactor storage basket and the interbuilding coffin (IBC), is usually performed during reactor operation. Normally, one subassembly is loaded into the primary tank and one removed per day while fuel handling is in progress.

The first definite pattern observed in monitoring the cover-gas impurities was numerous step increases in the nitrogen concentration. The plant log books showed that the step increases coincided in time with restricted fuel-handling operations. Comparison of data from the gas chromatograph with entries in the fuel-handling $10 \mathrm{~g}$ indicated that the major inleakage occurred when the fuel transfer port was opened, but some minor increases were observed during the time the argon from the FUM-ACS was routed through the transfer port for cleaning up the sodium adhering to the port. There was no nitrogen increase during a special test of repeated opening and closing of the transfer port. This discounted the possibility of air leakage past the seals of the transfer-port valves and indicated that the Increases were due to air contamination in the FUM-ACS. 


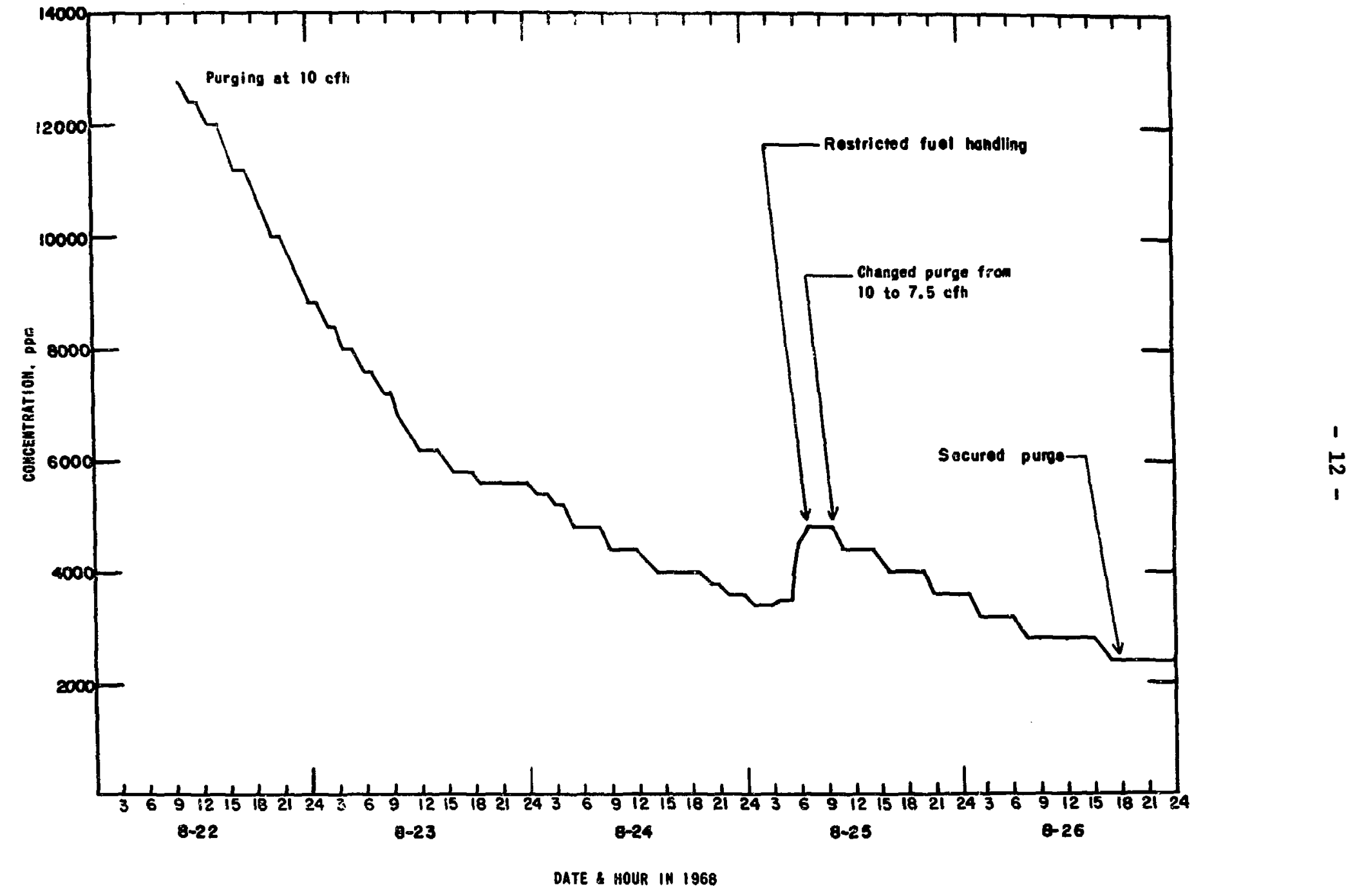

Fig. 3. Nitrogen Concentration in EBR-II Primary Cover Gas during a Purge of Approximately 10 cfh 


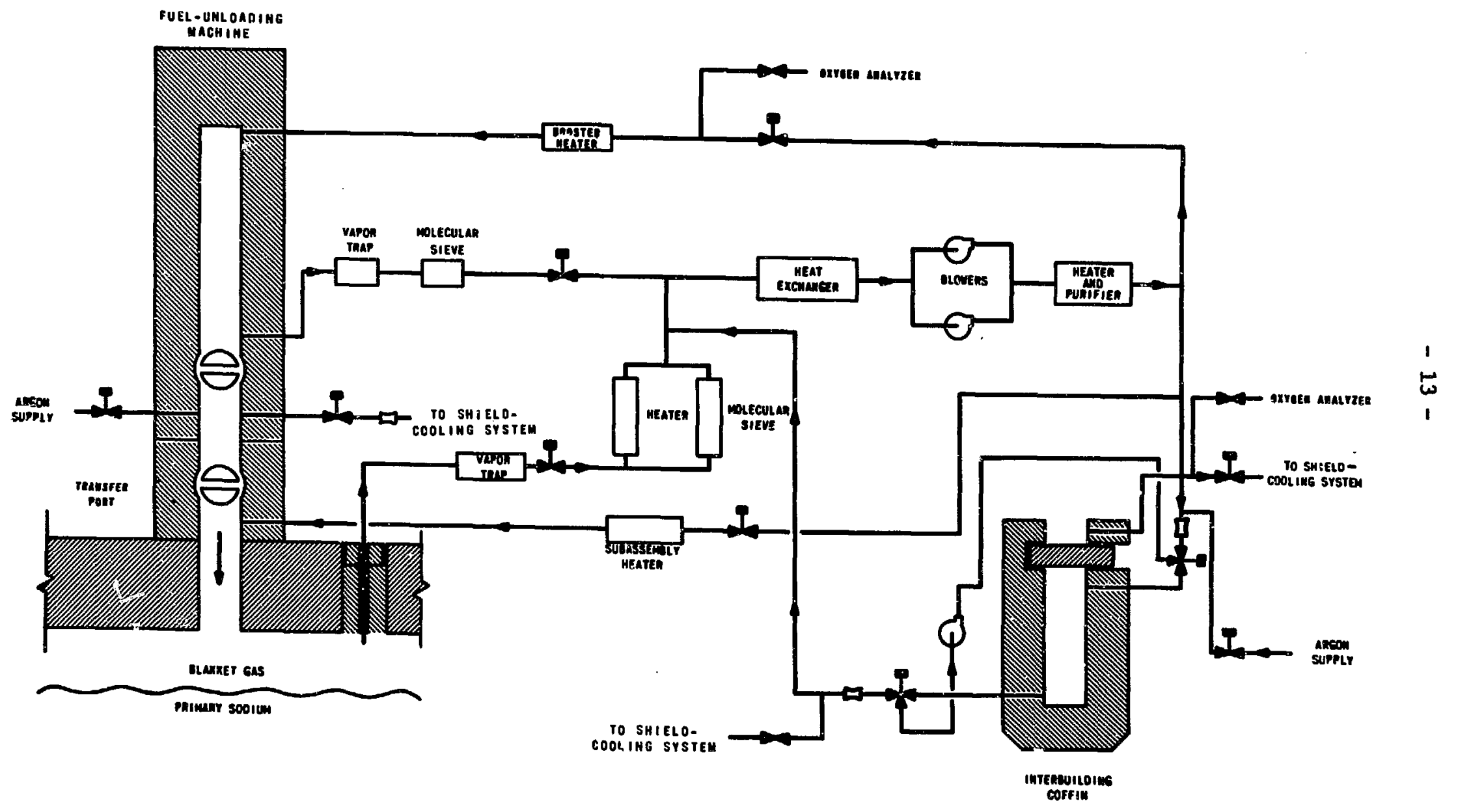

Fig. 4. Flow Diagram of Argon Cooling System for Fuel-unloading Machine 
Gas purity in the FUM-ACS is monitored with an oxygen meter. At the beginning of this study, operating procedures called for purging the FUiACS until the oxygen meter reglstered $40 \mathrm{ppm}$ before the fuel transfer port was opened. Any sodium in the system would greatly reduce oxygen content, would have less effect on hydrogen concentration, but would have almost no effect on nitrogen concentration. Thus, the oxygen meter would give a false indication that purging was complete, ard nitrogen would be transferred to the primary tank when the transfer port was opened.

Operating procedures were changed to require a purge of an additional $15 \mathrm{~min}$ after the oxygen meter reached $40 \mathrm{ppm}$. This change $1 \mathrm{n}$ procedures reduced the frequency of step increases in nitrogen during restricted fuel handling from a rate of about $45 \%$ to a rate of about $14 \%$ of the transfers.

Figure 5 shows the nitrogen concentrations in the primary cover gas during three subassembly transfers. These data illustiate nitrogen behavior during (a) a large step increase, (b) a small step increase, and (c) no increase.

During the first part of this study, there was a considerably higher probability of nitrogen being introduced into the primary tank during the first fuel transfers after a FUM-ACS cooldown than during subsequent fuel transfers with a hot FUM-ACS. However, the change in purging procedure has made the probability of nitrogen introduction about equal for these two conditions.

\section{Unrestricted Fuel Handling}

Unrestricted fuel handling is performed to refuel the reactor with fresh subassemblies. It includes the transfer of subassemblies between the reactor core and the storage basket, and all operations are done under the sodium surface within the primary tank. Movement of the rotating plugs, fuel gripper, and holddown is required to complete a transfer of a subassembly to or from the reactor core. The reactor is shut down during unrestricted fuel handling.

Before January 1971, a gradual increase in nitrogen concentration was always observed during unrestricted fuel handing. Figure 6 shows a typical increase. Air inleakage during raising and lowering of the gripper and/or the subassembly holddown was considered to be the most 1ikely 


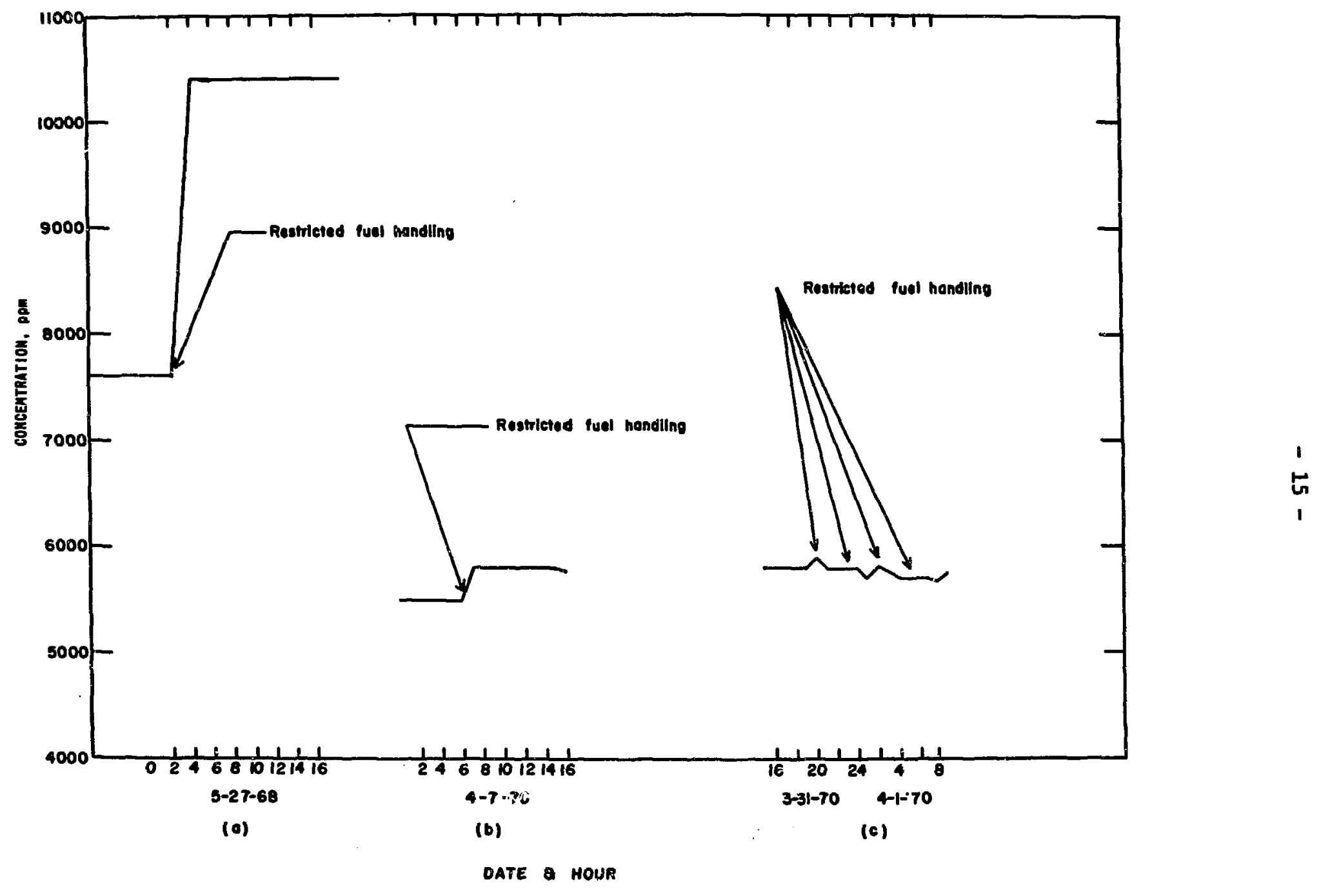

Fig. 5. Nitrogen Concentration in EBR-II Primary Cover Gas during Restricted Fuel Handling: (a) Large Step Increase, (b) Small Step Increase, (c) No Increase 


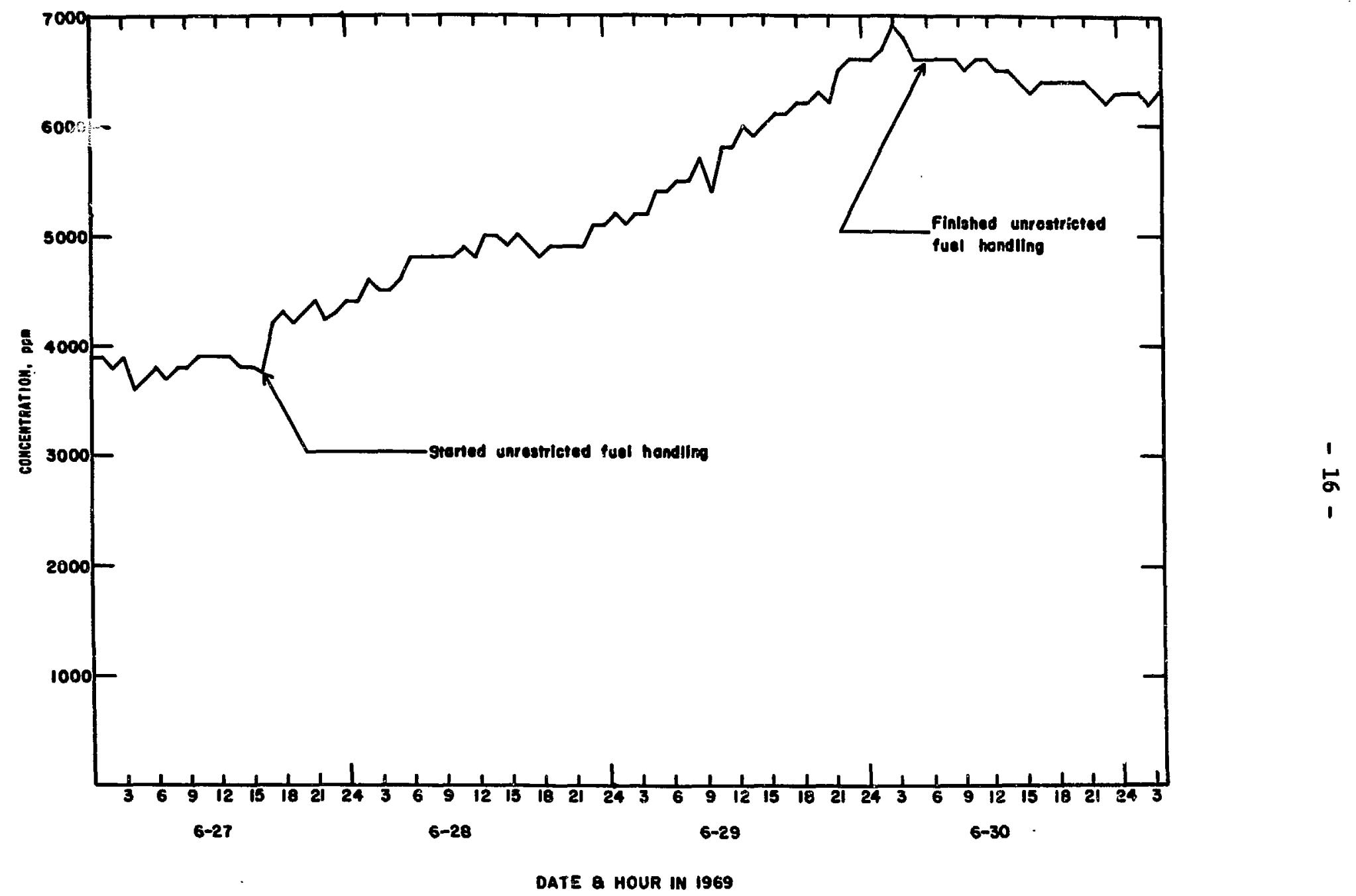

Fig. 6. Typical Behavior of Nitrogen Concentration in EBR-II Primary Cover Gas during Unrestricted Fuel Handling: Before Modification of Subassembly Holddown 
source of nitrogen. The holddown was the prime suspect, because there appeared to be the possibility of a pumping action during its operation, which would force air through the mecisanical packing gland into the primary tank. Also, the holddown was becoming sticky, which indicated that sodium oxide was building up on the mechanism.

The subassembly holddown was modified during the scheduled long reactor shutdown for maintenance at the end of 1970. Relief holes were irilled in the shroud tube to eliminate the possibility of pumping action during operation. (This is the same modification that was successfully made to the gripper when considerable sticking of that unit was experienced In 1963.) There have been no observed increases in nitrogen concentration during unrestricted fuel handling since this modification was completed.

\section{Reactor Operation}

There has been a gradual decrease in nitrogen concentration during most periods of reactor operation. Figure 7 is typical of the trend that has been observed. Of course, restricted fuel handling is usually done during periods of reactor operation, so step increases in nitrogen concentration are often superimposed on the long-term gradual decrease.

The nitrogen decrease during reactor operation is undoubtedly due to dilution of the primary cover gas by makeup argon. However, the lack of precise measuring devices in the gas system and the fluctuations in rate of argon makeup for the primary cover gas during plant operation and maintenance make an accurate quantitative description impossibla to achieve.

There are essentially two ways in which the primary cover gas can be diluted with fresh argon. First, any leakage from the primary tank is replaced with plant argon. This argon is fed to the receiver tank, but it eventually reaches the primary tank through the purge to the primarypump seals (see Fig. 1). A total of 8-10 $\mathrm{cfh}\left(63-79 \mathrm{~cm}^{3} / \mathrm{sec}\right)$ flows from the receiver tank, through the primary-pump seals, and into the primary tank, but most of this amount of flow returns from the primary tank to the receiver tank, via the floating-head tank.

The rate of leakage of gas from the primary system, and hence the rate of makeup, is not constant. Maintenance and replacement of seals, etc. can have a significant effect on the leakage rate. For instance, a test 


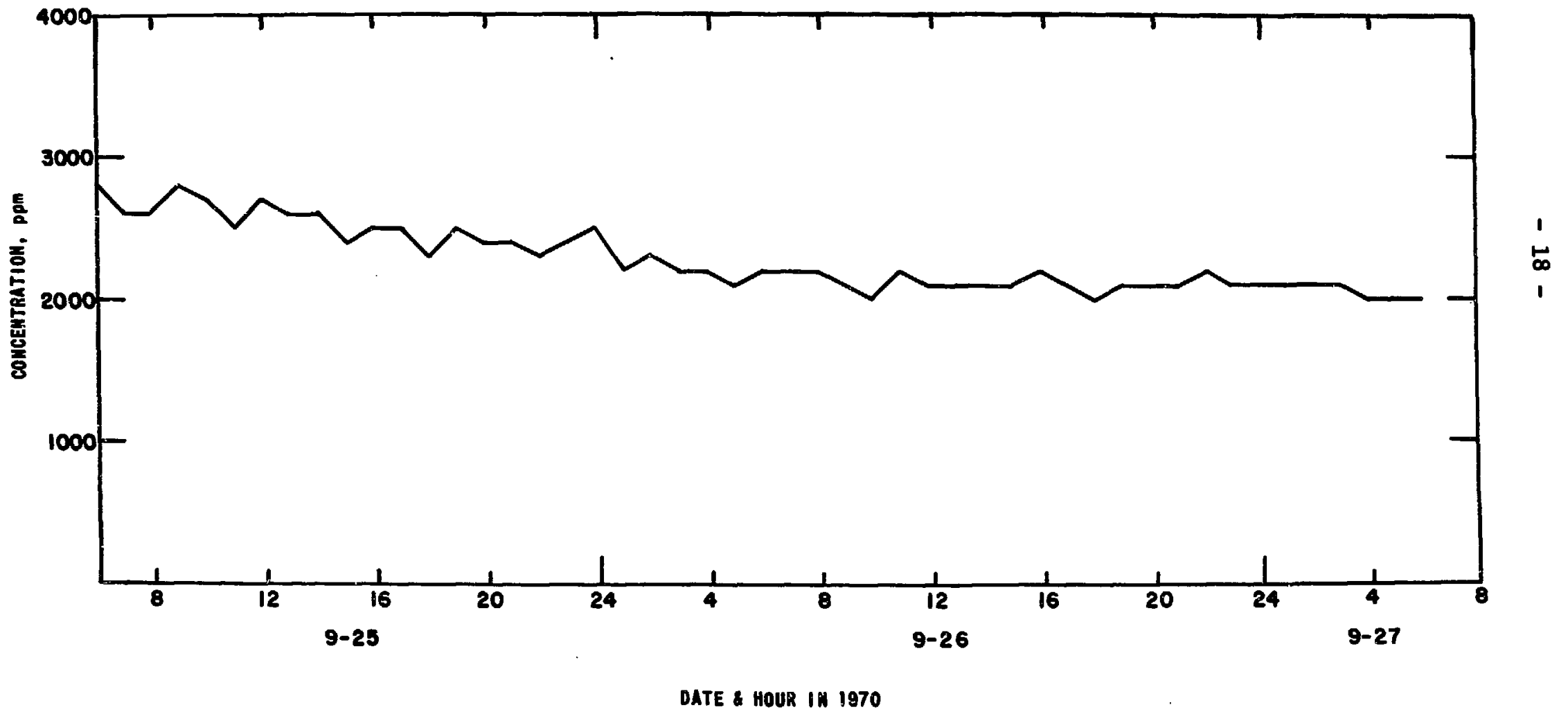

Fig. 7. Typical Nitrogen Concentration in EBR-II Primary Cover Gas during Reactor Operation 
conducted in July 1968 indicated a leakage rate of about $10 \mathrm{cth}(79 \mathrm{~cm} / \mathrm{sec})$ during reactor operation and no fuel handling. In comparison, a test conducted in March $197 \mathrm{I}$ under the same operating conditions indicated a leakage rate of about $1 \mathrm{cfh}\left(8 \mathrm{~cm}^{3} / \mathrm{sec}\right)$. Although there is considerable uncertainty In the data, they do show that the leakage rate is not constant.

The second way in which the primary cover gas can be diluted occurs during restricted fuel handling. The FUM-ACS is purged during each startup and often contains argon of higher purity than that in the primary tank. There is an exchange of gas between the FUM-ACS and the primary tank during fuel handiling, which results in a small improvement in the quality of the primary cover gas.

5. Leakage through the FUM-ACS and FGM Systems

Both the FUM-ACS and FGM systems pump gas irom the cover-gas plenum and then discharge the gas back Into the same space (see Figs. I and 2). The suction sides of the FGM pumps and the FUM-ACS turbines (when the system is valved into the cover gas) are under negative pressures. A leak in the suction side of either system results in air being pumped into the primary cover gas, which causes a rapid increase in the nitrogen concentration. Although the systems are normally sealed, a few leaks have occurred. Causes of the leaks were elther: fallure of a component (e.g., rupture of a diaphragm of a FGM pump), which caused the system to open to the atmosphere; or improper sealing around vapor traps and aerosol filters that had been installed as replacements.

To ensure system integrity, mandatory leak-checks are now required after maintenance. In addition, an alarm has been added to the primarygas chromatograph, and procedures have been changed to make possible early detection of air inleakage into either system.

\section{Miscellaneous}

Long reactor shutdowns are schetuled perlodically for plant mainrenance. The primary gas system is usually opened for one reason or another, and large step increases in nitrogen concentrations are sometimes observed. However, the nitrogen level is usually decreased quickly by the high purge rate that results from the increased leakage from the "open" system. 
The pressure of the primary cover gas was increased from $1-1 / 2$ to $2-1 / 2$ in. $\mathrm{H}_{2} \mathrm{O}$ as a special test during a short period of unrestricted fuel handling. Although the results were inconclusive, the rate of nitrogen buildup was less than the average rate of increase observed during unrestrlcted fuel handling. No further tests were made with increased covergas pressure, because the nitrogen buildup during unrestricted fuel handling was effectively eliminated by modifying the subassembly holddown (see Sec. II.A.3).

The rotating-plug seals are cleaned periodically to remove dross that accumulates in the troughs. There has been speculation that air was forced into the seal alloy during cleaning and was bubbling up on the inside of the seal trough. Review of the data from the gas chromatograph showed that there were no significant nitrogen increases that could be attributed to air inleakage during cleaning of the seals.

\section{B. Summary of Data from the Gas Chromatogranh}

Figures 8-13 show the average daily concentrations of nitrogen in the primary cover gas for the perlod March 21, 1968, through April 4, 1971. For orientation, the general plant conditions are shown above the plots.

\section{Studies on Nitridation}

Ruther ${ }^{6}$ demonstrated that nitriding of stainless steel in nitrogenblanketed sodium could occur and conducted a series of ex-reactor experiments to evaluate the nitriding potential under conditions approximating those in the primary tank. The results of his experiments indicate that only insignificant nitriding would be expected at a temperature of $700^{\circ} \mathrm{F}$ and a nitrogen concentration of a few thousand parts per million in argon cover gas.

The auxtliary gripper plug is the only EBR-II component that has been examined for evidence of nitridation after a long residence time in both the primary sodium and the cover gas. The plug was fabricated from Type 304 stainless steel and had been in the primary tank for approximately 70 months. Samples filed from the surface of the plug analyzed 0.03 wt \% nitrogen below the sodlum/gas interface, 0.063 wt \% at the interface, and 0.071 wt \% above the interface. Thus, there apparently has been very 


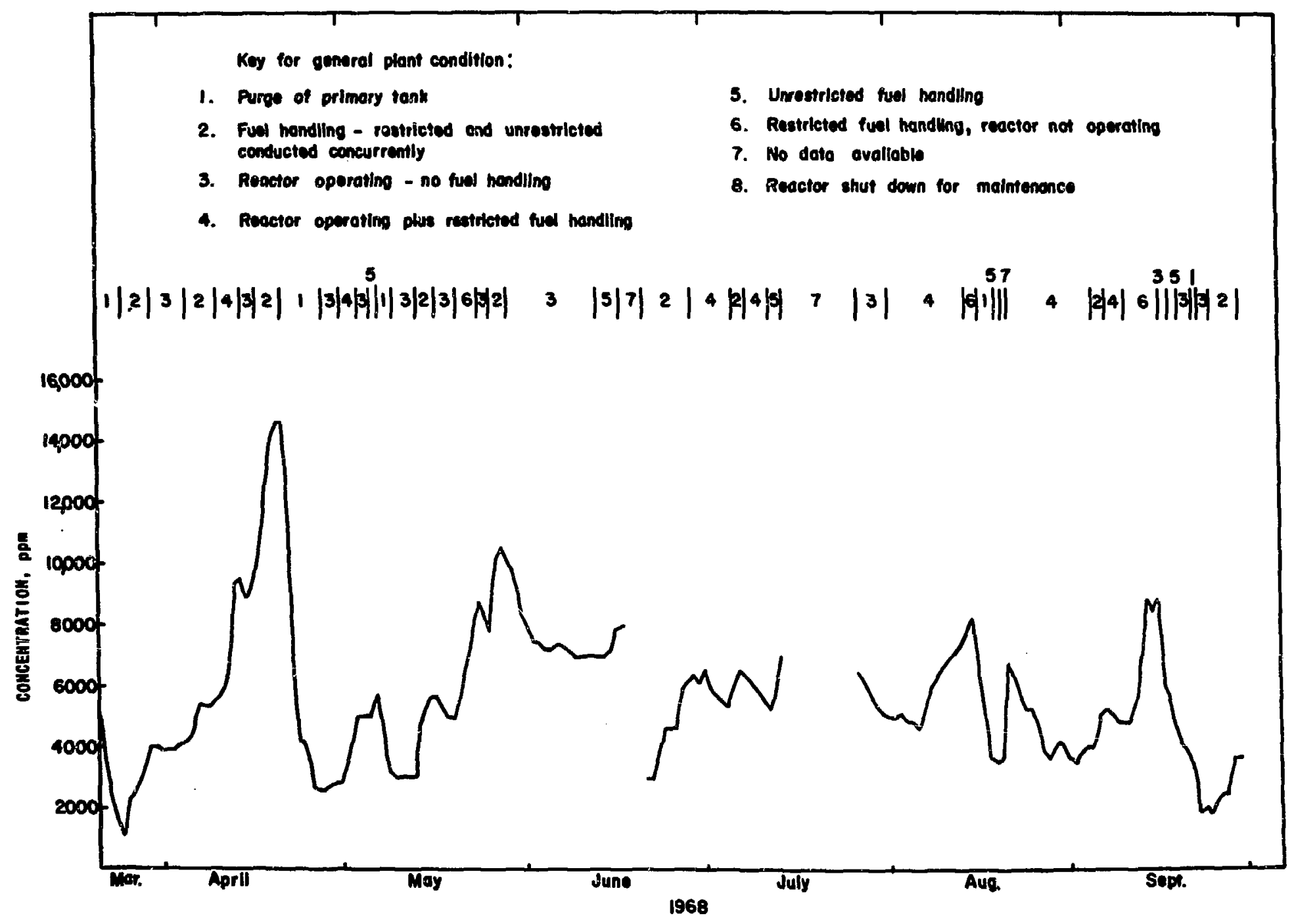

Fig. 8. Nitrogen Concentration In EBR-II Primary Cover Gas: March 1968-September 1968 


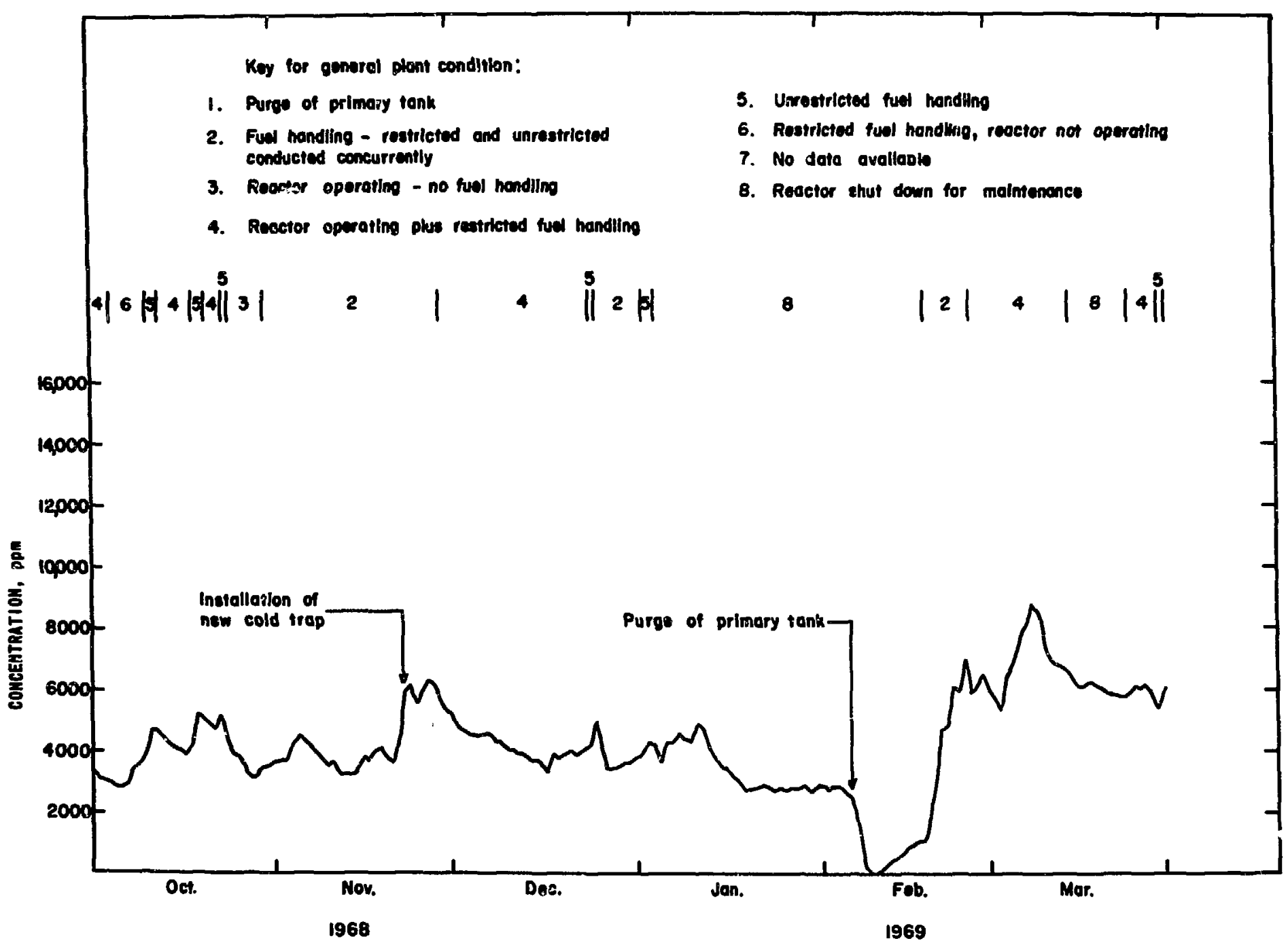

Fig. 9. Nitrogen Concentration In EBR-II Primary Cover Gas: October 1968-March 1969 


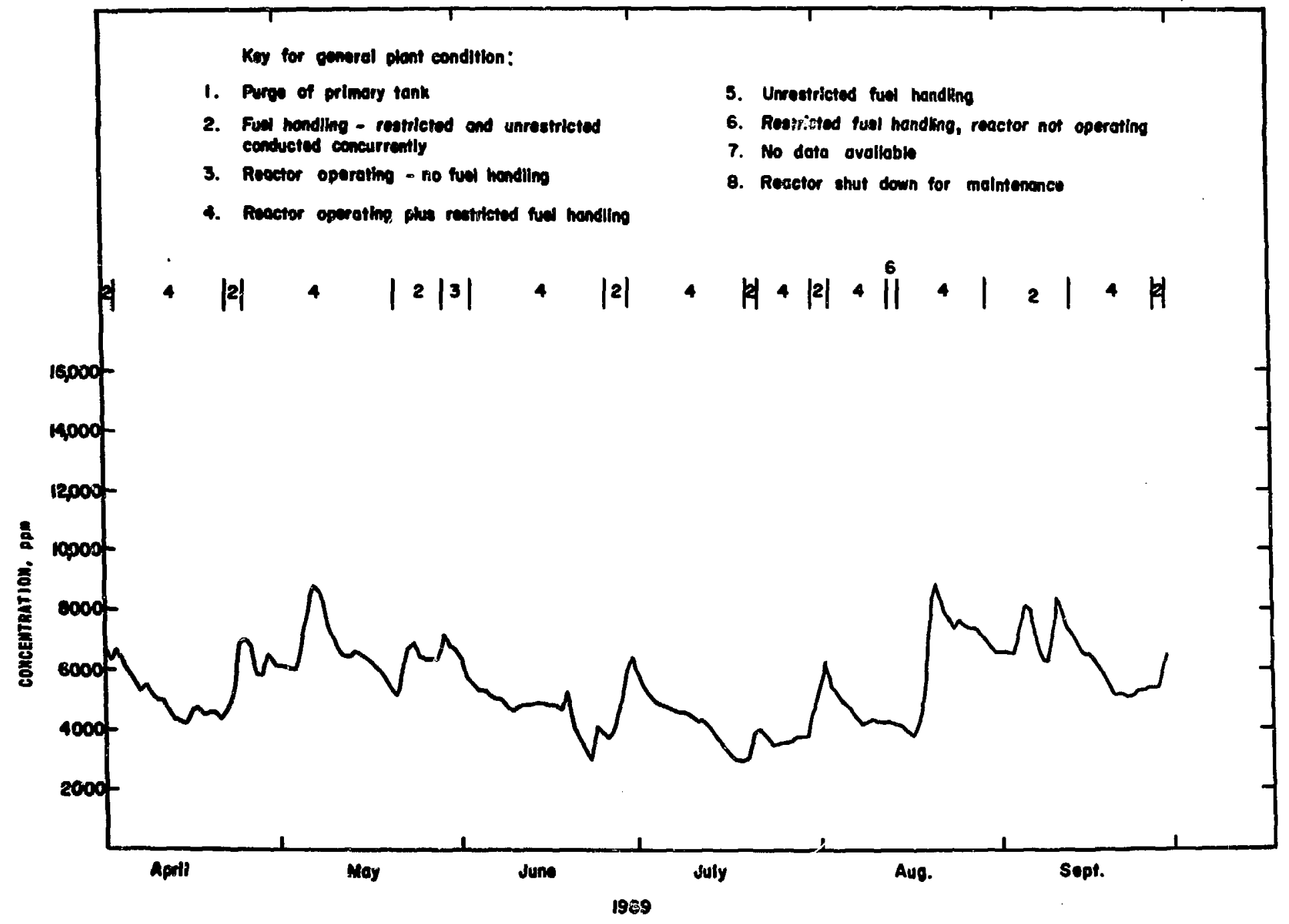

F18. 10. Nitrogen Concentration in EBR-II Primary Cover Gas: Apri1 1969-September 1969 


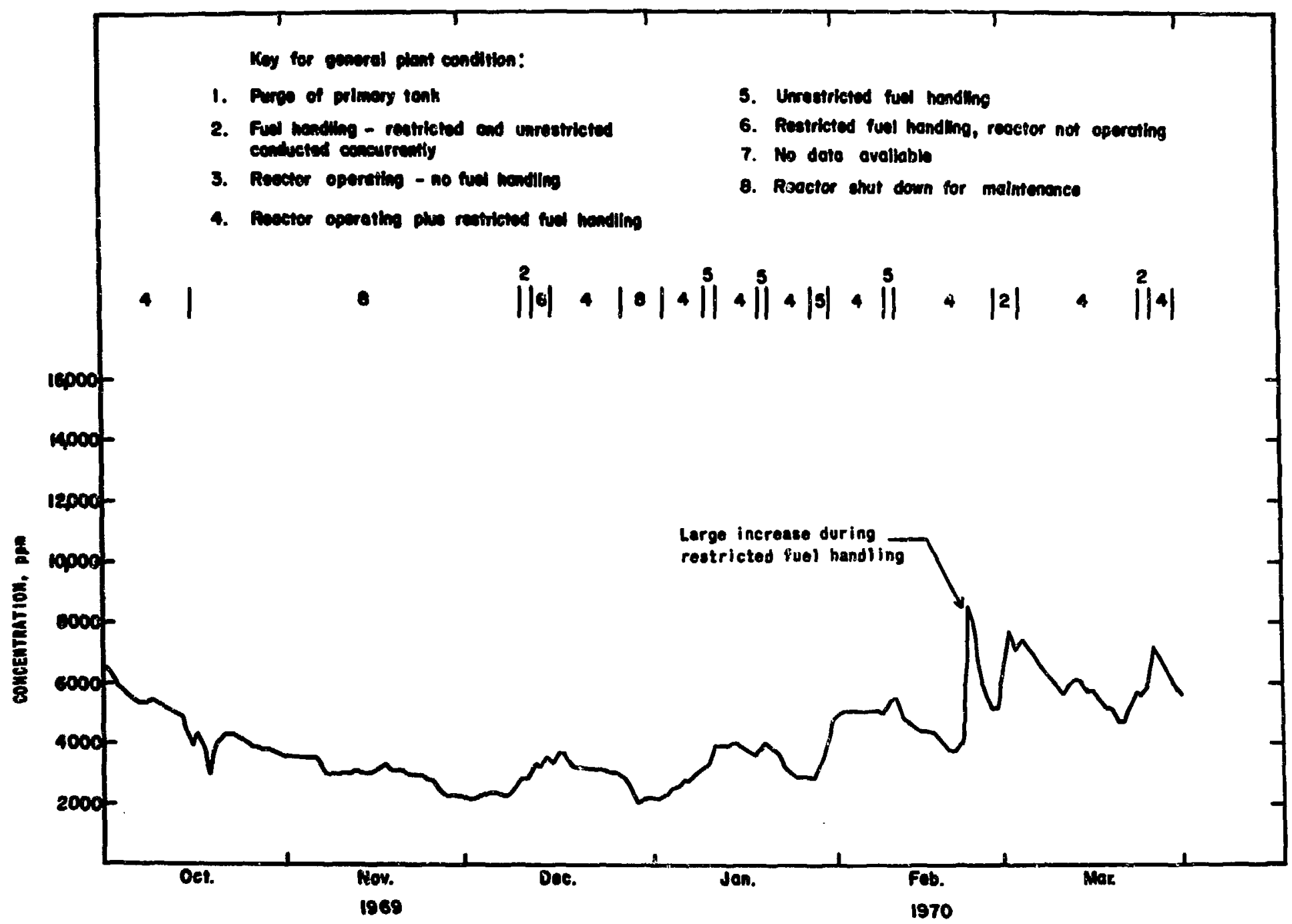

FIg. 11. Nitrogen Concentration In EBR-II Primary Cover Gas: October 1969-March 1970 


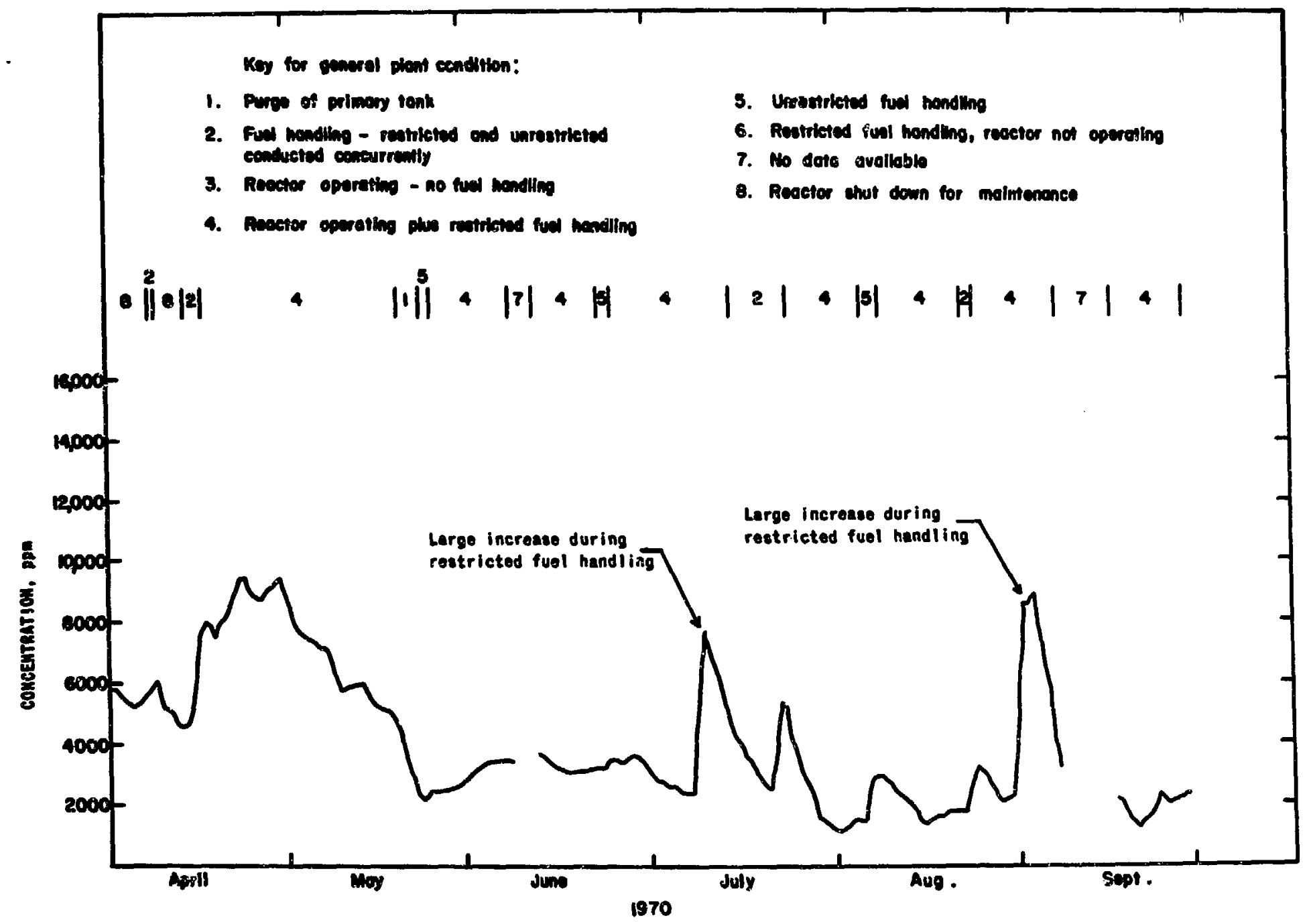

F1g. 12. N1trogen Concentration in EBR-II Primary Cover Gas: April 1970-September 1970 


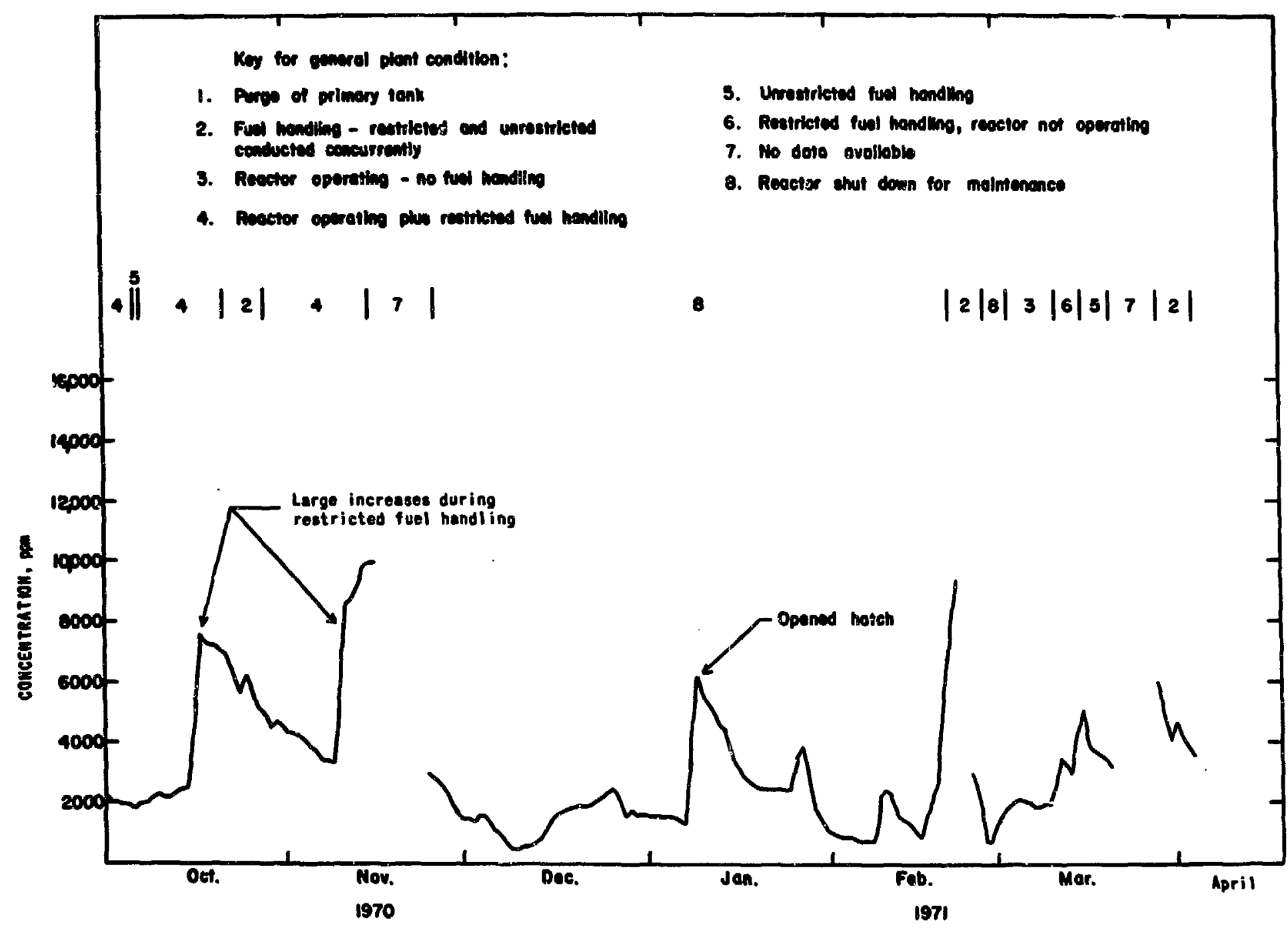

Fig. 13. Nitrogen Concentration In EBR-II Primary Cover Gas: Octoìer 1970-March 1971 
Iittle nitridation of stainless steel components in the primary tank, efther above or below the sodium level.

\section{HYDROGEN AND OXYGEN CONTAMINATION}

Hydrogen concentration in the primary cover gas is usually within the range of 10-20 ppm. Oxygen is usually below the level of detectibility of the gas chromatograph.

When step increases in the nitrogen concentration were first observed during restricted fuel handling, corresponding peaks of as high as $400 \mathrm{ppin}$ in hydrogen concentration occurred. It was noted, however, that the hydrogen peaks (or spikes) usually occurred when the IBC was used to transfer fuel to or from the primary tank via the FUM. This fact indicated that the hydrogen could be coming from molsture retained in the IBC after it had been dried in the Fuels and Examination Facility. To reduce the moisture carryover, an air preheater was installed in the IBC drying system, and operating procedures were changed to require that the IBC be dried with heated air until the molsture content drops below $500 \mathrm{ppan}$.

Although the Improved drying procedure has substantially reduced the magnitude and frequency of the hydrogen peaks, concentrations of hydrogen as high as 150-200 ppm are observed when the air and/or moisture enters the primary tank during restricted fuel handling.

Oxygen peaks as high as $200 \mathrm{ppm}$ also have been observed mainly during restricted fuel handling. High oxygen concentration is observed at only one datum point on the chromatograph recorder, which indicates that the oxygen is removed from the cover gas by the molten sodium within $8 \mathrm{~min}$. The hydrogen concentration is reduced exponentially, but does not reach equilibrium for 8-10 hr. Figure 14 shows typical spikes in hydrogen and oxygen concentrations observed on two separate occasions.

\section{CONCLUSIONS AND RECOMENDATIONS}

Impurity levels encountered in the primary cover gas have not been detrimental to the reactor components. There has been very little nitridation of components either above or below the sodium level. 
$-28-$

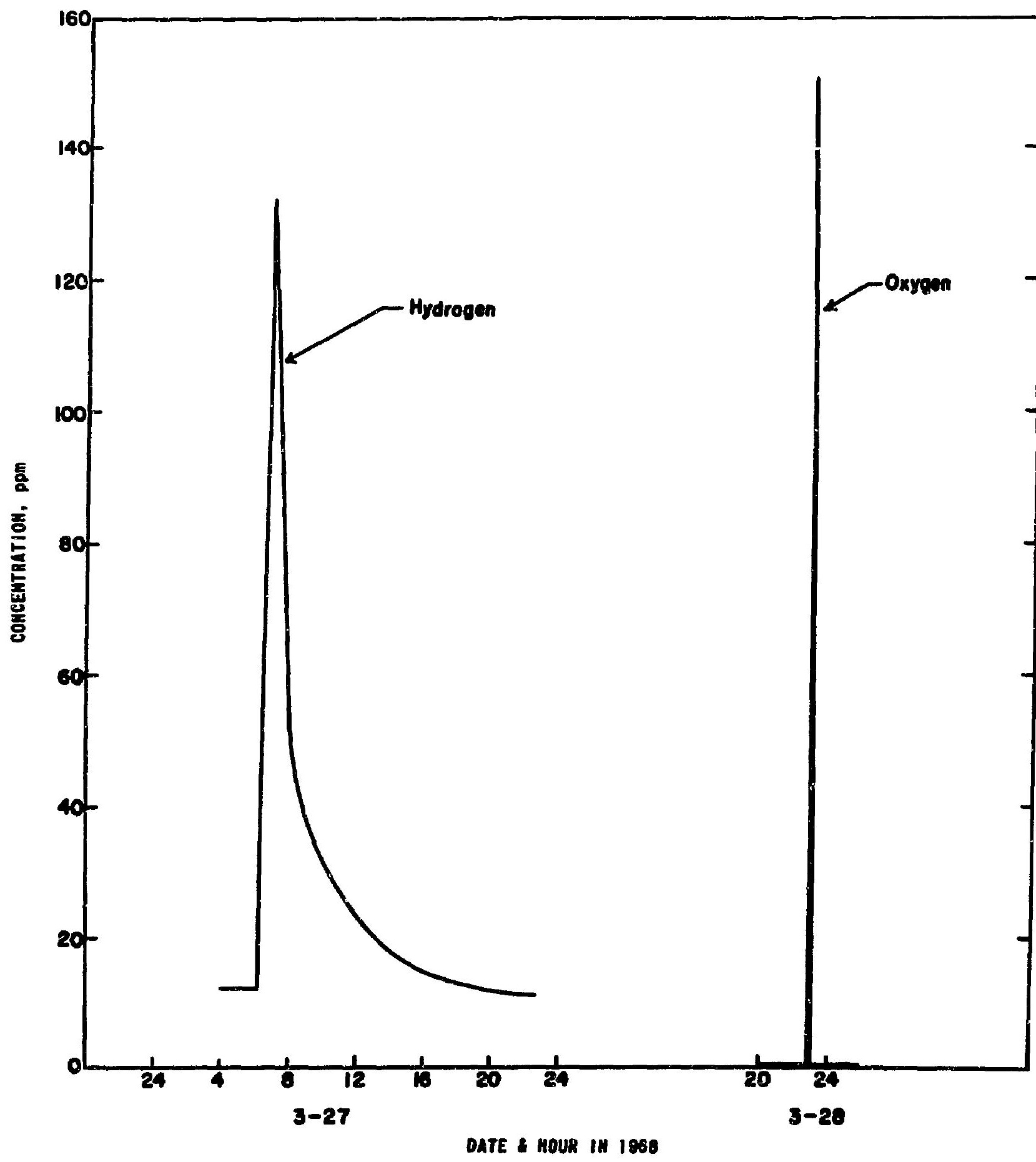

Fig. 14. Typical Increases in Hydrogen and Oxygen Concentration in EBR-II Primary Cover Gas then Fuel Transfer Port Is Opened 
Nitrogen concentration has been reduced considerably since close monttoring of Impurity levels in the cover gas began in 1968. The primary gas system appears to be quite tIght, and air inleakage during fuel handling has been greatly reduced. It appears as though the average nitrogen concentration can be maintained between 2000 and $3000 \mathrm{ppm}$, a concentration that would not cause deterioration of any of the components in the primary system.

Oxygen that enters the primary cover gas through air leakage is of some concern. Although the amount of oxygen contamination is not large enough to significantly affect the oxide concentration of the bulk sodium, oxidation of sodium on aurfaces of primary components penetrating the cover gas can occur. A certain quantity of sodium oxide 1 s also retained in the cover gas as aerosol, and a portion of this aerosol is deposited on the exposed surfaces of the primary components. Additional amounts are carried Into the FIM-ACS and FGM systems. Deposition and gradual bulldup of sodium oxide (in combination with sodium) on the working clearances of the primary pumps, gripper, holddown, etc. can eventually result in rubbing and binding of these components. A more Immediate problem is the plugging of 1 ines, vapor traps, and aerosol traps of the FUM-ACS and FGM systems with sodium oxide. The frequent replacement and cleaning of the affected units increases the downtime of these critical systems.

Continued close monitoring of the cover-gas impurities is planned. A continuing effort is being made to further reduce all sources of air leakage into the primary tank. Planned activitiss are Installation of wellcharacterized samples in the cover gas as long-term nitridation monitors and adittion of accurate measuring devices to provide a means of determining the rate of leakage from the primary gas system.

\section{ACKNOWLEDGEMENTS}

We acknowledge the assistance of R. K. Perrenoud and R. E. Hess in handling the data from the gas chromatograph. We also acknowledge the efforts of C. B. 2itek (Commonwealth Edison) who undertook the Initial Iuvestigation on impurities in the primary cover gas while on temporary ssignment to the BBR-II Project. 


\section{REFERENCES}

1. L. J. Koch et al., Hazard Sumnary Report, Experimental Breeder Reactor II (EBR-II), ANL-5719, Sec. III.A (May 1957).

2. L. J. Koch, W. B. Loewenstein, and H. O. Monson, Addendum to Hazard Summary Report, Experimental Breeder Reactor-II (EBR-II), ANL-5719 (Addendum), Sec. III.A (June 1962).

3. E. Hutter, P. Elias, D. J. Veith, and W. R. Ware, EBR-II Fuel-Unloading Machine: Design and Performance Characteristics, ANL-7201, pp . 59-57 (June 1966).

4. Operating Instructions for EBR-II, Sec. IV F, "Argon Purification" (EBR-II Project document).

5. EBR-II System Design Descript1ons, Vo1. II, "Primacy Systems," Chapter 7 . "Auxiliary Systems" (EBR-II Project document).

6. W. E. Ruther, T. D. Claar, S. Greenberg, and R. V. Strain, MaterialsCoolant Interactions Relevant to EBR-II, ANL-7771 (Apri1 1971). 